\title{
$\alpha$-Pinene nitrates: synthesis, yields and atmospheric chemistry
}

\author{
S. X. Ma ${ }^{1}$, J. D. Rindelaub ${ }^{1}$, K. M. McAvey ${ }^{1}$, P. D. Gagare ${ }^{1}$, B. A. Nault ${ }^{1}$, P. V. Ramachandran ${ }^{1}$, and P. B. Shepson ${ }^{1,2}$ \\ ${ }^{1}$ Department of Chemistry, Purdue University, 560 Oval Dr., West Lafayette, 47907, USA \\ ${ }^{2}$ Department of Earth and Atmospheric Sciences, Purdue University, 550 Stadium Mall Dr., West Lafayette, IN 47907, USA
}

Received: 1 February 2011 - Published in Atmos. Chem. Phys. Discuss.: 28 February 2011

Revised: 3 June 2011 - Accepted: 21 June 2011 - Published: 5 July 2011

\begin{abstract}
The biogenic volatile organic compound $\alpha$-pinene is one of the dominant monoterpenes emitted to the Earth's

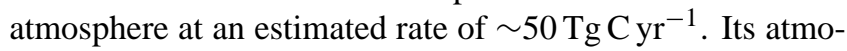
spheric oxidation products in the presence of $\mathrm{NO}$ can lead to ozone production, as well as production of secondary organic aerosol (SOA). The major oxidation pathway of $\alpha$-pinene is reaction with $\mathrm{OH}$, which in the presence of $\mathrm{NO}$ can form either $\alpha$-pinene nitrates or convert $\mathrm{NO}$ to $\mathrm{NO}_{2}$, which can photolyze to form ozone. In this work, we successfully synthesized four $\alpha$-pinene hydroxy nitrates through three different routes, and have identified these 4 individual isomers in $\alpha$-pinene/OH/NO reaction chamber experiments. From the experiments, we determined their individual production yields, estimated the total $\mathrm{RONO}_{2}$ yield, and calculated the relative branching ratios of the nitrate precursor peroxy radicals $\left(\mathrm{RO}_{2}\right)$. The combined yield of the four $\alpha$-pinene nitrates was found to be $0.130( \pm 0.035)$ at atmospheric pressure and $296 \mathrm{~K}$, and the total organic nitrate yield was estimated to be $0.19(+0.10 /-0.06)$. We also determined the $\mathrm{OH}$ rate constants for two of the isomers, and have calculated their overall atmospheric lifetimes, which range between 22 and $38 \mathrm{~h}$.
\end{abstract}

\section{Introduction}

Biogenic volatile organic compounds (BVOCs) account for more than $1200 \mathrm{TgC} \mathrm{yr}^{-1}$ of emitted carbon in the atmosphere (Guenther et al., 1993), which include isoprene $\left(\mathrm{C}_{5} \mathrm{H}_{8}\right)$, monoterpenes $\left(\mathrm{C}_{10} \mathrm{H}_{16}\right)$, and sesquiterpenes $\left(\mathrm{C}_{15} \mathrm{H}_{32}\right)$. Isoprene and monoterpenes account for over $50 \%$ of global BVOC emissions, with isoprene emitted at a rate of $\sim 500 \mathrm{Tg} \mathrm{C} \mathrm{yr}^{-1}$ and monoterpenes emitted at a rate of $\sim 127 \mathrm{Tg} \mathrm{C} \mathrm{yr}^{-1}$ (Guenther et al., 1993, 2006). While not as

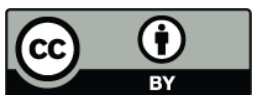

Correspondence to: $\mathrm{S} . \mathrm{X} . \mathrm{Ma}$ (ma58@purdue.edu) dominant as isoprene in terms of total emissions, global $\alpha$ pinene emissions of 50-60 $\mathrm{Tg} \mathrm{C} \mathrm{yr}^{-1}$ (Guenther et al., 1993, 2006) are on the order of global anthropogenic hydrocarbon emissions (Isaksen and Hov, 1987). In mid-latitude regions, such as the Mediterranean, $\alpha$-pinene has been measured to significantly exceed isoprene (Kalabokas et al, 1997; Owen et al., 1997; Seufert et al., 1997). When compared to isoprene, $\alpha$-pinene has $\sim 2$ times lower reactivity to the hydroxyl radical $(\mathrm{OH})$, but relatively higher reactivity to ozone $\left(\mathrm{O}_{3}\right)$ and nitrate $\left(\mathrm{NO}_{3}\right)$ radicals, making its atmospheric oxidation significant in the accounting of regional tropospheric $\mathrm{O}_{3}$ and $\mathrm{NO}_{\mathrm{x}}$ concentrations (Atkinson and Arey, 2003a,b). The oxidation products of $\alpha$-pinene, similar to other terpene species, have recently been determined to generate large amounts of secondary organic aerosols (SOA) in the atmosphere, which impacts the global radiation budget (Andreae and Crutzen, 1997; Larsen et al., 2001; Lee et al., 2006; Librando and Tringali, 2005; Pathak et al., 2007; Steinbrecher et al., 2009).

A BVOC (R-H) reacting with $\mathrm{OH}$ undergoes either hydrogen abstraction (Reaction R1) or OH-addition (Reaction R2) across an olefinic double bond (if present).

$$
\begin{aligned}
\mathrm{R}-\mathrm{H}+\mathrm{OH} & \rightarrow \mathrm{R} \cdot+\mathrm{H}_{2} \mathrm{O}(\text { hydrogen abstraction }) \\
\rightarrow & \mathrm{RHOH}\left(+\mathrm{O}_{2}\right) \rightarrow \mathrm{RO}_{2}(\mathrm{OH} \text { addition }) \\
\mathrm{R} \cdot+\mathrm{O}_{2} \rightarrow & \mathrm{RO}_{2} \\
\mathrm{RO}_{2}+\mathrm{NO}+\mathrm{M} & \rightarrow \mathrm{RONO}_{2}+\mathrm{M} \\
& \rightarrow \mathrm{RO} \cdot+\mathrm{NO}_{2}
\end{aligned}
$$

Both pathways can produce a radical that combines with $\mathrm{O}_{2}$ (Reaction $\mathrm{R} 3$ ) to form a peroxy radical $\left(\mathrm{RO}_{2}\right)$. Peroxy radical $\left(\mathrm{RO}_{2}\right)$ species originating from the $\mathrm{OH}$-initiated oxidation of BVOCs can react either with NO through Reactions (R4) and (R5) or, in the absence of $\mathrm{NO}_{\mathrm{x}}$, with $\mathrm{HO}_{2}$

Published by Copernicus Publications on behalf of the European Geosciences Union. 


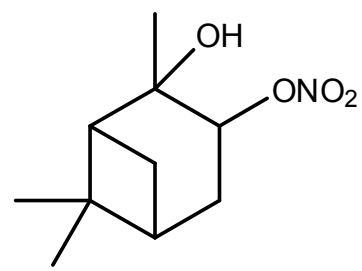

APN-A

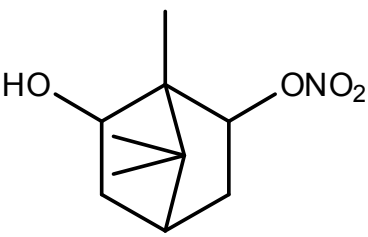

APN-C

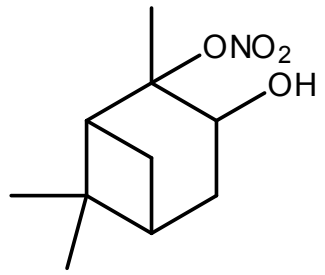

APN-B

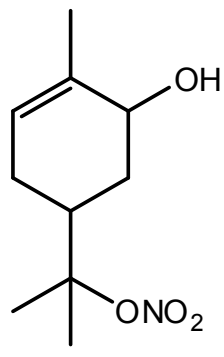

APN-D
Fig. 1. Structure of the four $\alpha$-pinene hydroxy nitrate isomers.

or $\mathrm{RO}_{2}$ to produce an organic peroxide or carbonyl compound and alcohol (Atkinson and Arey, 2003a,b). $\mathrm{RO}_{2}$ reaction with $\mathrm{NO}$ forms an unstable peroxy nitrite intermediate $\left[\mathrm{ROONO}^{*}\right]$ that decomposes into $\mathrm{NO}_{2}$ and RO. (Reaction R5) or, less often, will rearrange to form a stable organic nitrate (Reaction R4) (Atkinson et al., 1982; Barker et al., 2003; Monks et al., 2009). The organic nitrate, $\mathrm{RONO}_{2}$, formed from Reaction $\mathrm{R} 4$ can serve as a reservoir of $\mathrm{NO}_{\mathrm{x}}$ in the atmosphere. Although this pathway is often treated as a termination step in the oxidation pathway, it is likely that significant $\mathrm{NO}_{\mathrm{x}}$ recycling occurs through further reactions with radical species, such as $\mathrm{OH}$, as well as via photolysis (Horowitz et al., 2007; Monks et al., 2009).

At present, much is unknown regarding the $\alpha$-pinene oxidation mechanism. Previous laboratory studies of $\alpha$-pinene oxidation products (Aschmann et al., 2002; Grosjean et al., 1992; Hakola et al., 1994; Hatakeyama et al., 1991; Larsen et al., 2001; Lee et al., 2006; Nozière et al., 1999; Reissell et al., 1999; Ruppert et al., 1999; Orlando et al., 2000; Wisthaler et al., 2001; van den Bergh et al., 2000; Vinckier et al., 1998) focused on the yields of one or more key $\alpha$-pinene aldehyde and ketone products such as pinonaldehyde, formaldehyde, and acetone. Aschmann et al. (2002) and Nozière et al. (1999) presented the only studies of the total gas-phase organic nitrate yields from $\alpha$-pinene oxidation initiated by $\mathrm{OH}$ attack. However, the data from the two studies are considerably divergent $(<1 \%$ for Aschmann et al. (2002) and $18 \%$ for Noziere et al., 1999), necessitating further experimental study of the reaction mechanism for $\alpha$ pinene nitrate formation.
In this work, we have successfully synthesized four $\alpha$ pinene hydroxy nitrates. They were separated, identified and detected in photochemical reaction chamber experiments. The individual production yields, total $\mathrm{RONO}_{2}$ yield and the value for the branching ratios $(\alpha)$ were determined. We also measured the rate coefficients for the reaction of $\mathrm{OH}$ radical with two $\alpha$-pinene hydroxy nitrates at atmospheric pressure and $296 \mathrm{~K}$.

\section{Experimental}

\subsection{Synthesis of $\alpha$-pinene hydroxy nitrates}

We developed three methods to synthesize $\alpha$-pinene hydroxy nitrates (APNs). Four compounds were synthesized: 2-hydroxypinene-3-nitrate (APN-A), 3hydroxypinene-2-nitrate (APN-B), 6-hydroxy-1,7,7trimethylbicyclo[2.2.1] heptan-2-yl nitrate (APN-C), and 6-hydroxymenthen-8-nitrate (APN-D) (Fig. 1). The synthetic procedures applied in this study are modifications of several techniques (Wängberg et al., 1997; Constantino et al., 2007; Rollins et al., 2010a) and are described in detail therein. All the reagents used for the synthesis and chromatography were obtained from Sigma-Aldrich (at analytical grade) and were used without further purification. The ${ }^{1} \mathrm{H}$ and ${ }^{13} \mathrm{C}$ NMR spectra were recorded with a Varian Inova $300 \mathrm{MHz}$ spectrometer using $\mathrm{CDCl}_{3}$ as the solvent.

Method 1: Method 1 employs $\alpha$-pinene diol (99\%) as the starting reagent for the synthesis of APN-A (Wängberg et al., 1997). The basic principle underlying this technique is the use of mild nitration reactions that differentiate between two unequivalent $\mathrm{OH}$ groups in the reagent diol. A solution consisting of $17 \mathrm{ml} 65 \% \mathrm{HNO}_{3}$ in $24 \mathrm{ml}$ acetic anhydride was prepared by dropwise addition of $\mathrm{HNO}_{3}$ and stirred. It was subsequently cooled to $0^{\circ} \mathrm{C}$ via a methanol bath in a CryoCool immersion cooler before a solution containing $1.3 \mathrm{~g} \alpha$-pinene diol dissolved in $25 \mathrm{ml}$ acetic anhydride was added. The mixture was stirred for 15 minutes at $0-10{ }^{\circ} \mathrm{C}$ and poured onto an ice salt mixture into a separatory funnel. The mixture was extracted with $140 \mathrm{ml}$ diethyl ether. The organic fraction was washed with 3 small portions of brine solution and dried over $\mathrm{Na}_{2} \mathrm{SO}_{4}$. The product, APN-A, was purified by column chromatography on silica gel (hexane:ethyl acetate, 9:1).

Method 2: $\alpha$-Pinene hydroxy nitrates were also prepared using reactions between $\alpha$-pinene epoxide (97\%) with $\mathrm{NbCl}_{5}$ (99\%) (Constantino et al., 2007) followed by silver nitrate. A solution of $\alpha$-pinene epoxide $(1.52 \mathrm{~g}, 10.00 \mathrm{mmol})$ in anhydrous ethyl acetate $(10 \mathrm{ml})$ was added to a solution of niobium pentachloride $(1.35 \mathrm{~g}, 5.00 \mathrm{mmol})$ in anhydrous ethyl acetate $(10 \mathrm{ml})$ (maintained at $-78^{\circ} \mathrm{C}$ and under nitrogen atmosphere). The reaction mixture was stirred at the same temperature for $5 \mathrm{~min}$. The reaction mixture was quenched with $20 \mathrm{ml}$ of a 1:1 water:THF solution. The 


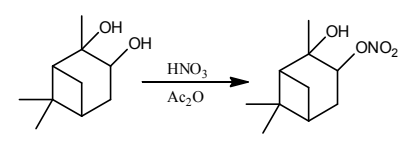

method 1
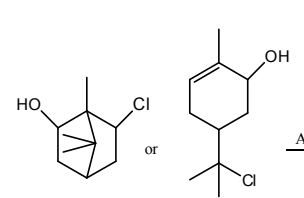

APN-A
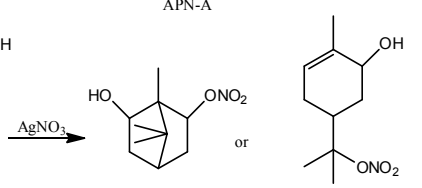

method 2

II APN-C APN-D

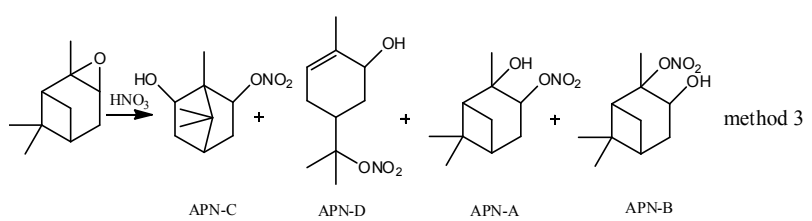

Fig. 2. $\alpha$-Pinene hydroxy nitrate synthesis chemistry.

mixture was diluted with water and ethyl acetate. The organic layer was separated and washed three times with $10 \mathrm{ml}$ aliquots of $5 \%$ aqueous sodium bicarbonate and twice with $10 \mathrm{ml}$ aliquots of brine solution $(\mathrm{NaCl})$. The organic layer was then dried over anhydrous sodium sulfate. The solvent was removed under vacuum, and the products were purified by silica gel column chromatography using a mixture of hexane and ethyl acetate (8:2) as eluent to give the chlorohydrins (I and II in Fig. 2) as pale yellow oils.

Powdered silver nitrate, at a 2:1 molecular ratio, was added to the chlorohydrins (I or II) in $10 \mathrm{ml}$ pure dry ether, and the solution was stirred at room temperature overnight to yield the products APN-C and APN-D.

Method 3: $\alpha$-Pinene hydroxy nitrates were prepared by nitration of $\alpha$-pinene epoxide (Rollins et al., 2010a). A $25 \mathrm{ml}$ round bottom flask was flame dried, equipped with a stir bar, and a solution was added containing $6.52 \mathrm{mmol}(1.07 \mathrm{ml})$ of $\alpha$-pinene oxide in $8 \mathrm{ml}$ of dry diethyl ether. $3 \mathrm{ml}$ of dry diethyl ether and 7.39 mmols $(0.3 \mathrm{ml})$ of fuming nitric acid were added to another separate flame dried $25 \mathrm{ml}$ round bottom flask, equipped with a stir bar. Under nitrogen, these flasks were cooled to $-94^{\circ} \mathrm{C}$ via a hexane/LN 2 bath. After cannulating the acid solution into the epoxide solution, the new mixture was kept at $-94{ }^{\circ} \mathrm{C}$ for an additional hour. The reaction flask was then allowed to warm to room temperature over $12 \mathrm{~h}$. The solution was washed several times with sodium bicarbonate to remove excess $\mathrm{HNO}_{3}$ and then dried over sodium sulfate. Flash chromatography was extensively used for separating and obtaining $\alpha$-pinene hydroxy nitrates. This synthesis procedure generated four $\alpha$-pinene hydroxy nitrate isomers. A pure APN-C was purified by silica gel column chromatography.

Identification of the two pure $\alpha$-pinene hydroxy nitrates (APN-A and APN-C) was accomplished using ${ }^{1} \mathrm{H}$ and ${ }^{13} \mathrm{C}$ NMR and GC-MS (EI, CI and negative CI). APN-D was identified using GC-MS analysis, which indicated a $104 \mathrm{~m} / \mathrm{z}$ fragment $\left(\left(\mathrm{CH}_{3}\right)_{2} \mathrm{C}^{+}-\mathrm{ONO}_{2}\right)$, and by comparison of the chromatograms from Method 2 and Method 3 using a Varian 450-GC with a thermionic specific detector (GC-TSD), yielding a product nitrate with the same retention time and the same elution temperature $\left(\sim 245^{\circ} \mathrm{C}\right)$; additionally, Method 2 could only yield product APN-D from the corresponding chlorohydrin II. The fourth $\alpha$-pinene hydroxy nitrate produced from Method 3 was determined as isomer APN-B, with a structure similar to APN-A, because of the similar mass spectrum and given that it is a possible product from Method 3. Figures 1 and 2 show the structure of the four synthesized $\alpha$-pinene hydroxy nitrates and the $\alpha$-pinene hydroxy nitrates synthesis chemistry.

\subsection{Photochemical reaction chamber experiments}

A 55001 Teflon photochemical reaction chamber was used to determine the yield of $\alpha$-pinene nitrates from the reaction of $\mathrm{OH}$ with $\alpha$-pinene in the presence of NO. UV radiation was provided to the chamber using 12 solar simulator lamps (UVA-340) surrounding the chamber. $\alpha$-Pinene, isopropyl nitrite (IPN) and $\mathrm{NO}$ were injected into the chamber in a stream of $\mathrm{N}_{2}$ to avoid oxidation of $\mathrm{NO}$ to $\mathrm{NO}_{2}$. Initial concentrations were $200 \mathrm{ppb}$ to $2 \mathrm{ppm}$ of $\alpha$-pinene, $20 \mathrm{ppm}$ of IPN, and $200 \mathrm{ppb}$ to $2 \mathrm{ppm}$ of NO. IPN was used as the source of OH radicals, as shown in Reactions (R6)-(R8) below. The chamber was irradiated for periods of 5 to $15 \mathrm{~min}$ and left dark during periods of analysis to suppress the production of $\mathrm{O}_{3}$ and $\mathrm{NO}_{3}$, ensuring that all $\alpha$-pinene was consumed via reaction with $\mathrm{OH}$ and all $\mathrm{RO}_{2}$ react with $\mathrm{NO}$.

$$
\begin{array}{ll}
\mathrm{CH}_{3} \mathrm{CH}(\mathrm{ONO}) \mathrm{CH}_{3}+\mathrm{h} v & \rightarrow \mathrm{CH}_{3} \mathrm{CH}(\mathrm{O} \cdot) \mathrm{CH}_{3}+\mathrm{NO} \\
\mathrm{CH}_{3} \mathrm{CH}(\mathrm{O} \cdot) \mathrm{CH}_{3}+\mathrm{O}_{2} & \rightarrow \mathrm{CH}_{3} \mathrm{C}(\mathrm{O}) \mathrm{CH}_{3}+\mathrm{HO}_{2} \\
\mathrm{HO}_{2}+\mathrm{NO} & \rightarrow \mathrm{OH}+\mathrm{NO}_{2}
\end{array}
$$

The consumption of $\alpha$-pinene during the photochemical reaction chamber experiments was measured using a HP 5890 Series II gas chromatograph with a flame ionization detector (GC-FID) that employed a RTX-1 column $(30 \mathrm{~m}, 0.53 \mathrm{~mm}$ i.d., $1.0 \mu \mathrm{m}$ film thickness, Restek). $\mathrm{NO}$ and $\mathrm{NO}_{\mathrm{x}}$ concentrations were determined using a Chemiluminescence NO$\mathrm{NO}_{2}-\mathrm{NO}_{\mathrm{x}}$ Analyzer (Model 42, Thermo Environmental Instruments Inc, Franklin, MA). A UV Photometric $\mathrm{O}_{3}$ Analyzer (Model 49, Thermo Environmental Instruments Inc, Franklin, MA) was used to determine ozone concentrations throughout the experiment.

A Varian 450-GC with a thermionic specific detector (GCTSD), which is specific for nitrogen and phosphorus compounds, was employed using a RTX-1701 column $(30 \mathrm{~m}$, $0.32 \mathrm{~mm}$ i.d., $1.0 \mu \mathrm{m}$ film thickness, Restek) to separate, identify and quantify the synthesized $\alpha$-pinene nitrates. Samples were injected from a $10 \mathrm{ml}$ sample loop connected to a 6-port valve. The GC temperature program was as follows: $80^{\circ} \mathrm{C}$ for $2 \mathrm{~min}, 20^{\circ} \mathrm{C} \mathrm{min}^{-1}$ to $250^{\circ} \mathrm{C}$, and held at $250^{\circ} \mathrm{C}$ 
for $5 \mathrm{~min}$. The PFA-Teflon sample line and the $10 \mathrm{ml}$ sample loop were heated to $70^{\circ} \mathrm{C}$ and $100^{\circ} \mathrm{C}$, respectively, to avoid surface losses. The GC-TSD inlet, sample loop, and column were conditioned with a large gas phase concentration of the synthesized $\alpha$-pinene nitrates to alleviate adsorptive losses of the APNs during experiments (Muthuramu et al., 1993). The GC-TSD was calibrated using the pure synthesized 2hydroxypinene-3-nitrate (APN-A) prepared in a PFA-Teflon bag. We then assume identical sensitivity for all the $\alpha$-pinene nitrates.

The total and individual $\alpha$-pinene nitrate yields were determined using GC-TSD sampling from the photochemical reaction chamber. The GC peak assignments were conducted by comparing chromatograms from the synthesized APN standards with those from $\alpha$-pinene/ $/ \mathrm{NO}_{\mathrm{x}}$ irradiation chamber experiments.

\subsection{OH rate constant experiments}

The rate constants for the reaction of $\alpha$-pinene hydroxy nitrates with $\mathrm{OH}$ were determined using the relative rate method (Aschmann and Atkinson, 2008). OH radicals were generated via photolysis of hydrogen peroxide $\left(\mathrm{H}_{2} \mathrm{O}_{2}\right)$ and approximately $\sim 200-500 \mathrm{ppb}$ of each synthesized $\alpha$ pinene hydroxy nitrate was rapidly injected into the chamber. Toluene and benzene were used as the relative rate reference compounds for APN-A and APN-C, respectively. The compounds were allowed to mix for $5 \mathrm{~min}$. The mixture was irradiated with solar simulator lamps that surround the reaction chamber. The peak heights for the APNs were determined throughout the experiment using GC/TSD as described above. The consumption of the relative rate reference compound during the photochemical reaction chamber experiments was measured using GC-FID as described above.

$\frac{1}{t} \cdot \ln \left\{\frac{\mathrm{APN}_{0}}{\mathrm{APN}_{\mathrm{t}}}\right\}=\frac{1}{t} \cdot \frac{k_{\mathrm{APN}}}{k_{\mathrm{REF}}} \ln \left\{\frac{\mathrm{REF}_{0}}{\mathrm{REF}_{\mathrm{t}}}\right\}+k_{w 1}$

The APN rate constants were determined by plotting $(1 / \mathrm{t}) \cdot \ln \left([\mathrm{APN}]_{0} /[\mathrm{APN}]_{t}\right) \quad$ vs. $(1 / \mathrm{t}) \cdot \ln \left([\mathrm{REF}]_{0} /[\mathrm{REF}]_{t}\right)$ and fitting the data linearly. $\mathrm{APN}_{0}, \mathrm{REF}_{0}, \mathrm{APN}_{t}$, and $\mathrm{REF}_{t}$ are the concentrations of each APN isomer and reference compound (REF) at time $t_{0}$ and $t$, respectively. The slope and intercept of the least squares fit were equal to $k_{\mathrm{APN}} / k_{\mathrm{REF}}$ and $k_{\mathrm{wl}}$, respectively. Equation (1) shows the relative rate equation, where $k_{\mathrm{wl}}$ is the appropriate first order APN wall loss rate constant $\left(\mathrm{s}^{-1}\right)$. The $\mathrm{OH}$ rate constants used for the reference compounds were $5.63( \pm 0.26) \times 10^{-12} \mathrm{~cm}^{3}$ molecules ${ }^{-1} \mathrm{~s}^{-1}$ (toluene) and $1.22( \pm 0.09) \times 10^{-12} \mathrm{~cm}^{3}$ molecules ${ }^{-1} \mathrm{~s}^{-1}$ (benzene) (Atkinson and Arey, 2003a).

\section{Results and discussion}

Six experiments involving the $\mathrm{OH}$ oxidation of $\alpha$-pinene in the presence of $\mathrm{NO}$ were conducted in the photochemical reaction chamber. During each experiment, samples were taken from the chamber at $15 \mathrm{~min}$ intervals.

A typical chromatogram from an $\alpha$-pinene/OH/NO irradiation experiment is shown in Fig. 3. The four identified $\alpha$-pinene nitrates eluted from the column at retention times ranging from $\sim 10-11 \mathrm{~min}$. The letters in Fig. 3 correspond to the APNs produced in the yield experiment, 2-hydroxypinene-3-nitrate (APNA), 3-hydroxypinene-2-nitrate (APN-B), 6-hydroxy-1,7,7trimethylbicyclo[2.2.1]heptan-2-yl nitrate (APN-C), and 6hydroxymenthen-8-nitrate (APN-D) (Fig. 1). Some isopropyl nitrate, which elutes at $\sim 4.0 \mathrm{~min}$, was also produced from the 2-propoxy radicals generated by the photolysis of isopropyl nitrite. This nitrate was not included in the integrated total organic nitrate concentration. A major objective for this study was the determination of the yields and peroxy radical rection branching ratios $\left(k_{4} /\left(k_{4}+k_{5}\right)\right)$ for the identified individual APN isomers.

\subsection{Possible reaction mechanism}

Here we propose and discuss the likely mechanism supporting a major result of this work, which is the identification and quantification of $\alpha$-pinene hydroxy nitrates A-D. The products of reaction of $\alpha$-pinene and $\mathrm{OH}$ radicals in the presence of NO include two $\alpha, \beta$-hydroxy nitrates named APN-A and APN-B, as well as two hydroxy nitrates from rearrangement, named APN-C and APN-D. In particular, identification of APN-C and APN-D has important implications for the $\alpha$ pinene oxidation mechanism.

The degradation of $\alpha$-pinene is initiated primarily by the $\mathrm{OH}$ radical addition to the $\mathrm{C}=\mathrm{C}$ double bond, producing the $\alpha$-pinene-OH adduct radicals that can lead to either $\mathrm{P} 1 \mathrm{OH}$, a secondary radical, or $\mathrm{P} 2 \mathrm{OH}$, a tertiary radical, as seen in Fig. 4. The $\mathrm{P} 1 \mathrm{OH}$ adduct will react rapidly with $\mathrm{O}_{2}$, forming the corresponding peroxy radical $\mathrm{R} 1$. Under atmospheric conditions with $\mathrm{NO}$ present, peroxy radical R1 will quickly form a peroxynitrite that will, in part, isomerize to nitrate APN-A. The major pathway of the peroxynitrite is dissociation to form the alkoxy radical and $\mathrm{NO}_{2}$. The subsequent $\mathrm{C}-\mathrm{C}$ bond cleavage in the alkoxy radical (proposed by Nozière et al., 1999) and $\mathrm{O}_{2}$ addition produces pinonaldehyde, a compound that is expected to be a major product under atmospheric conditions.

The tertiary radical, $\mathrm{P} 2 \mathrm{OH}$, can react rapidly with $\mathrm{O}_{2}$, forming the corresponding peroxy radical R2 (Fig. 4). R2 will quickly react to form a peroxynitrite in the presence of $\mathrm{NO}$, of which a minor fraction will, as noted above, isomerize to form nitrate APN-B. The major pathway of the peroxynitrite is dissociation to the alkoxy radical and $\mathrm{NO}_{2}$. The very fast subsequent $\mathrm{C}-\mathrm{C}$ bond cleavage of the alkoxy radical, followed by reaction with molecular oxygen, yields pinonaldehyde, as discussed above for the similar $\mathrm{P} 1 \mathrm{OH}$ mechanism. 

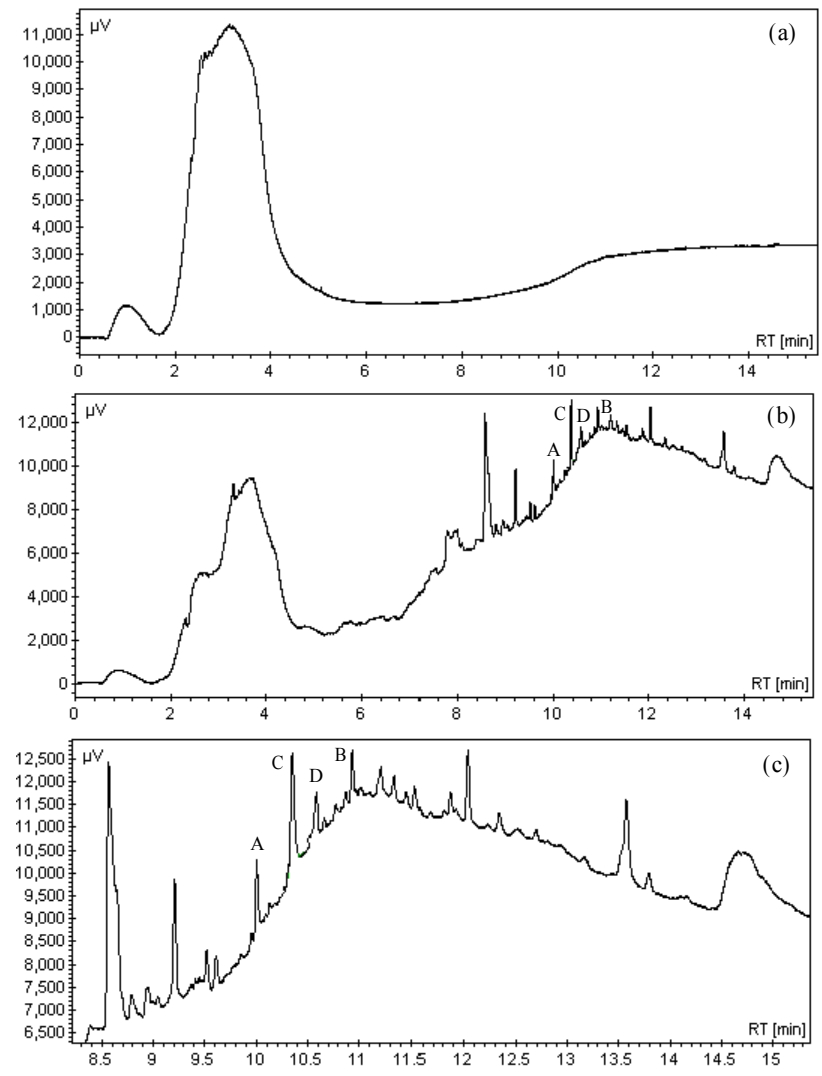

Fig. 3. GC-TSD chromatograms for an $\alpha$-pinene/OH/NO yield experiment. The letters correspond to the APNs identified and produced in the yield experiment. (a) blank chromatogram prior to irradiation; (b) the entire chromatogram after irradiation; (c) part of chromatogram (8.5-15 $\mathrm{min})$ above.

However, as discussed by Peeters et al. (2001) and Vereecken et al. (2007), ring strain for radical $\mathrm{P} 2 \mathrm{OH}$ can be relieved by either of the two pathways: migration of the isopropyl group or ring opening. Migration of the isopropyl group could involve an isomerization of the chemically activated $\mathrm{P} 2 \mathrm{OH}$ to its isomer $\mathrm{P} 3 \mathrm{OH}$ (Fig. 4), followed by rapid reaction with $\mathrm{O}_{2}$, forming the corresponding peroxy radical R3. Under atmospheric conditions with NO present, this peroxy radical R3 will quickly react to produce a peroxynitrite that will, in part, isomerize to nitrate APN-C. The major pathway of the peroxynitrite will be dissociation to the alkoxy radical and $\mathrm{NO}_{2}$. The subsequent $\mathrm{C}-\mathrm{C}$ bond cleavage of the alkoxy radical followed by reaction with $\mathrm{O}_{2}$ yields campholenealdehyde and, ultimately, nitrate APN-E. This isomerization has previously been proposed by Van den Bergh et al. (2000) and Vanhees et al. (2001) to explain their observed yield of campholenealdehyde from $\alpha$-pinene. Ring opening of $\mathrm{P} 2 \mathrm{OH}$ is believed to account for approximately $30 \%$ of this adduct, forming 6-hydroxymenthen-8-yl radical $\mathrm{P} 4 \mathrm{OH}$, which reacts with $\mathrm{O}_{2}$ to form the 6-hydroxymenthen8-peroxyl radical R4. R4 can then form the nitrate APN-D or a 6-hydroxymenthen-8-oxy radical, which can then dissociate to acetone and a 2-methyl-3-hydroxycyclohex-1-en-5-yl radical. That radical can further react with $\mathrm{O}_{2}$ and $\mathrm{NO}$ to yield a nitrate APN-F and an alkoxy radical, which will react further to produce a hydroxy-cyclohexenone. More recent work (Vereecken et al., 2007; Aschmann et al., 1998), however, indicates that ring closure reactions by the R4 peroxy radical may also lead to the formation of a six-membered ring.

Another channel for the reaction of $\alpha$-pinene with $\mathrm{OH}$ radicals occurring $5 \%$ of the time is $\mathrm{H}$-abstraction, leading to a $\alpha$-pinenyl radical and $\mathrm{H}_{2} \mathrm{O}$. These $\alpha$-pinenyl radicals can then combine with $\mathrm{O}_{2}$ to form a peroxy radical, which will quickly react with NO to form a peroxynitrite that will, in part, isomerize to an alkyl nitrate. In Fig. 4, we show the production of APN-G, as one example. As discussed below, the overall yield of alkyl nitrates resulting from $\mathrm{H}$-atom abstraction is estimated to be $\sim 0.9 \%$.

\section{$3.2 \alpha$-pinene nitrate yields}

Each measured APN concentration was corrected for consumption by $\mathrm{OH}$ using the method described by Atkinson et al. (1982). For any individual nitrate, $\mathrm{APN}_{i}$, we have the following reactions accounting for individual isomeric APN production.

$$
\begin{array}{ll}
\mathrm{OH}+\alpha \text {-pinene }+\mathrm{O}_{2} & \rightarrow \gamma_{i} \cdot \mathrm{RO}_{2, i} \\
\mathrm{RO}_{2, i}+\mathrm{NO} & \rightarrow \mathrm{RONO}_{2, i} \\
& \rightarrow \mathrm{RO}_{i}+\mathrm{NO}_{2}
\end{array}
$$

Here $\gamma_{i}$ is the fractional yield of the appropriate precursor peroxy radical. Assuming steady state in $\mathrm{RO}_{2, i}$, and where " $\mathrm{R}$ " represents the reaction rate, $\mathrm{R}_{9} \cdot \gamma_{i}=\mathrm{R}_{10}$ and $\mathrm{R}_{9}=k_{9}[\mathrm{OH}][\alpha$-pinene $]$. Equation (2) describes the $\alpha$-pinene decay rate.

$$
\begin{aligned}
& -d[\alpha-\text { pinene }] / d t=\mathrm{R}_{10} / \gamma_{i}=k_{10}\left[\mathrm{RO}_{2, i}\right][\mathrm{NO}] / \gamma_{i} \\
& d\left[\mathrm{RONO}_{2, i}\right] / d t=\mathrm{R}_{10 \mathrm{a}}=k_{10 \mathrm{a}}\left[\mathrm{RO}_{2, i}\right][\mathrm{NO}]
\end{aligned}
$$

If $\Delta\left[\mathrm{RONO}_{2, i}\right]$ vs. $-\Delta[\alpha$-pinene $]$ is plotted, the slope of the least squares fit $=k_{10 \mathrm{a}}\left[\mathrm{RO}_{2, i}\right][\mathrm{NO}] /\left(k_{10}\left[\mathrm{RO}_{2, i}\right][\mathrm{NO}] / \gamma_{i}\right)$ $=\gamma_{i} \cdot k_{10 \mathrm{a}} / k_{10}$. Thus if $\gamma_{i}$ is known, the branching ratio for $\mathrm{RONO}_{2, i}$ formation, $\alpha_{i}=k_{10 \mathrm{a}} / k_{10}$, can be determined. If $\Delta \Sigma\left[\mathrm{RONO}_{2, i}\right]$ vs. $-\Delta[\alpha$-pinene $]$ is plotted, the slope of the least squares fit is equal to the overall average ( $\gamma$-weighted) branching ratio $\alpha$. The resulting plot for all the six experiments is shown in Fig. 5, revealing a slope of $0.130 \pm 0.035$ and thus a total yield for these four $\alpha$-pinene hydroxy nitrates of $13.0( \pm 3.5) \%$. The concentrations of each individual isomer, APNs A-D, were plotted against the loss of $\alpha$-pinene to obtain the individual yields, which are listed in Table 1 . The uncertainties reported above and in Table 1 represent the propagated 1s uncertainties from all known and estimated sourcs of error in these experiments. 


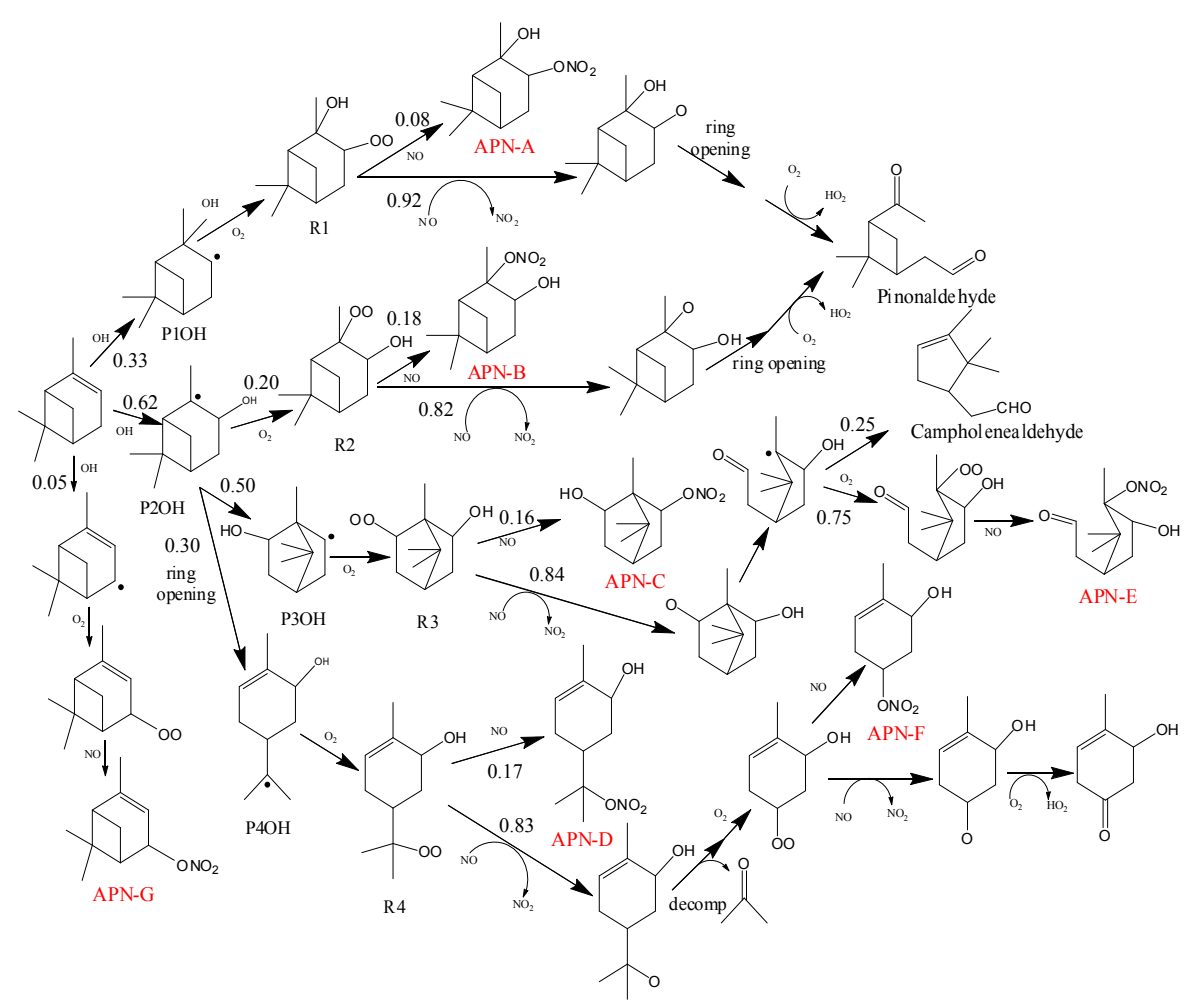

Fig. 4. Schematic of the mechanism for the OH-initiated degradation of $\alpha$-pinene to first generation products in the presence of NO.

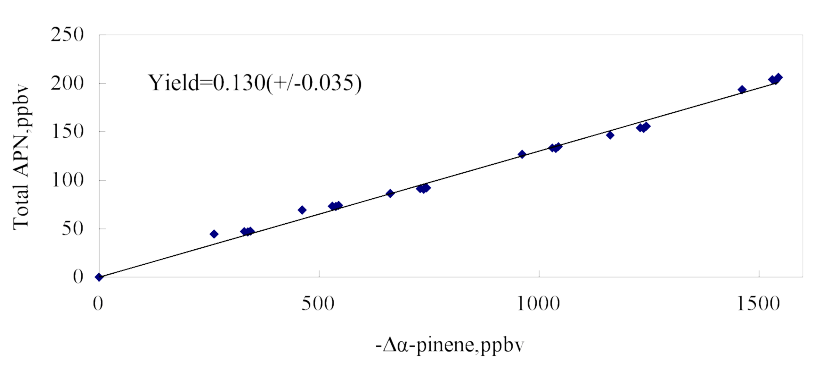

Fig. 5. Total $\alpha$-pinene nitrate yield. Total $[\mathrm{APN}]$ is plotted vs. the loss of $\alpha$-pinene over time. The data plotted are from multiple experiments.

\section{3 $\mathrm{RO}_{2}+\mathrm{NO}$ branching ratios}

The relationship between size and structure of organic peroxy radicals and the branching ratio $\alpha$ has been studied for simple molecules, but not as much for multiply functionalized $\mathrm{RO}_{2}$ radicals due to difficulty in measurements (Espada and Shepson, 2005). The branching ratio, $\alpha=k_{4} /\left(k_{4}+k_{5}\right)$, has been measured for several alkyl and $\beta$-hydroxy peroxy radical species (O'Brien et al., 1998; Arey et al., 2001; Aschmann et al., 2001). Previous experimental work by O'Brien et al. (1998) and Arey et al. (2001) has shown that the branching ratio increases with increasing carbon num- ber for both alkyl and $\beta$-hydroxy alkyl peroxy radicals. In an empirical mechanistic model, Zhang et al. (2004) found a linear dependence between the branching ratio and carbon number $(\mathrm{CN})$ of $\alpha=0.0174 \cdot \mathrm{CN}+0.0088$ for $\mathrm{C}_{1}$ to $\mathrm{C}_{7}$ systems. Aschmann et al. (2001) performed experiments to determine three different $\mathrm{C}_{10}$ alkyl nitrate branching ratios with an average branching ratio of $0.233 \pm 0.040$. This is $\sim 30 \%$ higher than the estimated value (0.18) from the Zhang et al. (2004) linear relationship for a $\mathrm{C}_{10}$ compound.

In Table 1, we list the individual calculated yields, from the plots of $\Delta\left[\mathrm{RONO}_{2, i}\right]$ vs. $-\Delta[\alpha$-pinene $]$. As discussed in Peeters et al. (2001) and Vereecken et al. (2007), a structureactivity relationship indicates that $95 \%$ of the $\mathrm{OH}+\alpha$-pinene reactions occur by addition across the double bond rather than through abstraction of a hydrogen atom. After $\mathrm{OH}$ addition, $\mathrm{O}_{2}$ adds to the other carbon atom associated with the double bond. According to Kwok and Atkinson (1995), the calculated site-specific $\mathrm{OH}$-addition ratio is 65:35 in favor of $\mathrm{P} 2 \mathrm{OH}$ formation. It has been estimated (Peeters et al., 2001; Vereecken et al., 2007) that $\sim 30 \%$ of the APN-B precursor $\mathrm{P} 2 \mathrm{OH}$ rearranges to form the APN-D precursor radical $\mathrm{P} 4 \mathrm{OH}$ and $\sim 50 \%$ of the APN-B precursor rearranges to form the APN-C precursor radical $\mathrm{P3OH}$ (Fig. 4), and thus we estimate that the precursor radical $\mathrm{P} 2 \mathrm{OH}$ to APN-B is produced $20 \%$ of the time. We then can calculate the values for $\gamma_{i}$ for the precursor peroxy radicals for APN-B, APN-C, APN-D as 0.95 $0.65 \cdot 0.2=0.124 ; 0.95 \cdot 0.65 \cdot 0.5=0.309$ and 
$0.95 \cdot 0.65 \cdot 0.3=0.185$. The calculated value for $\gamma_{i}$ for APN-A is $0.95 \cdot 0.35=0.332$. The branching ratio $\alpha$ is then found by dividing the yield of individual APNs by the fraction of the time, $\gamma_{i}$, the precursor $\mathrm{RO}_{2}$ radical is formed in $\mathrm{OH}$-addition. Using these values for $\gamma_{i}$, the calculated $\alpha_{i}$ values for the $\alpha$ pinene hydroxy nitrates are shown in Table 1 . These agree reasonably well with what we expect from the literature, except for APN-B, for which we would expect the $\alpha_{i}$ to be similar to that for APN-A. Further relative branching ratio experimental studies should be pursued for $\alpha$-pinene and other monoterpenes to compare against this set of results. Additional studies of alkyl and alkene nitrates with carbon number $(\mathrm{CN}) \geq 10$ should be conducted to expand the branching ratio information, e.g. for other terpenes and sesquiterpenes. As this data set increases significantly, a more reliable structureactivity relationship may be developed and tested against observations.

\subsection{Total $\alpha$-pinene nitrate yields}

In the course of these experiments, an unidentified group of peaks with retention times of 8.5-10 min and 11-14 min was observed. Some of the peaks in our chromatogram may well be from internal abstraction by an RO, to form a dihydroxy nitrate (Matsunaga and Ziemann, 2010). The reaction scheme shown in Fig. 4 results in the expectation of predicted significant yields of two other nitrates, APN-E and APN-F (not identified here), from OH radical addition to $\alpha$ pinene. These two compounds were presumed to be present in the chromatogram in Fig. 3. The yield of the alkoxy radical formed from radical R3 in the presence of $\mathrm{NO}$ could be calculated as $0.309 \cdot(1-0.16)=0.26$. Vanhees et al. (2001) measured the yield of campholenealdehyde as $5.5( \pm 0.7) \%$, thus the fractional yield of the appropriate precursor peroxy radical to APN-E is $0.26 \cdot 0.84 \cdot 0.75=0.16$ (see Fig. 4). If we assume that the value for the branching ratio $\alpha$ is 0.16 , then the yield of nitrate APN-E will be 0.16.0.16=0.026. For nitrate APN-F, the yield of the alkoxy radical formed from radical R4 in the presence of $\mathrm{NO}$ can be calculated as $0.185 \cdot(1-0.17)=0.15$. If the alkoxy radical produced from R4 only follows the path shown in Fig. 4 and the value for the branching ratio $\alpha$ is 0.16 , then we calculate the yield for APN-F as $0.185 \cdot(1-0.17) \cdot 0.16=0.024$.

As discussed above, the production of $\mathrm{RO}_{2}$ radicals from abstraction of a hydrogen atom from a saturated carbon was calculated to occur $5 \%$ of the time, based on structureactivity relationships. According to the relationship between the branching ratio and carbon number (Zhang et al., 2004), $\alpha=0.0174 \cdot \mathrm{CN}+0.0088$, the yield of APN-G formed from $\mathrm{H}$-abstraction of $\alpha$-pinene can be calculated as $0.05 \cdot(0.0174 \cdot 10+0.0088)=0.009$. We can then calculate an estimate for the total $\alpha$-pinene nitrate yield as $0.009+0.024+0.026+0.130=0.19$. The actual yield could be larger to the extent that RO radical internal abstractions occur (to produce dihydroxy nitrates). However, our estimate
Table 1. $\alpha$-Pinene hydroxy nitrate data.

\begin{tabular}{lrrr}
\hline APN & $\begin{array}{r}\text { Calculated } \\
\text { Identification }\end{array}$ & $\begin{array}{r}\text { Individual } \\
\text { Relative } \mathrm{RO}_{2} \\
\text { Yield }(\gamma)\end{array}$ & $\begin{array}{r}\text { Calculated } \\
\mathrm{RO}_{2}+\mathrm{NO} \\
\text { Branching } \\
\text { Ratio }(\alpha)\end{array}$ \\
\hline APN-A & $0.332 \pm 0.096^{\mathrm{a}}$ & $0.027 \pm 0.011$ & $0.08 \pm 0.04$ \\
APN-B & $0.124 \pm 0.037$ & $0.022 \pm 0.008$ & $0.18 \pm 0.08$ \\
APN-C & $0.309 \pm 0.059$ & $0.049 \pm 0.019$ & $0.16 \pm 0.07$ \\
APN-D & $0.185 \pm 0.043$ & $0.031 \pm 0.013$ & $0.17 \pm 0.08$ \\
APN-E & $0.16^{\mathrm{b}}$ & $0.026^{\mathrm{b}}$ & $0.16^{\mathrm{c}}$ \\
APN-F & $0.15^{\mathrm{b}}$ & $0.024^{\mathrm{b}}$ & $0.16^{\mathrm{c}}$ \\
APN-G & 0.05 & $0.009^{\mathrm{b}}$ & $0.18^{\mathrm{b}}$ \\
\hline
\end{tabular}

a uncertainties are expressed as $\pm 1 \mathrm{~s},{ }^{\mathrm{b}}$ calculated value, ${ }^{\mathrm{c}}$ assumed value

of 0.19 is consistent with the Nozière et al. (1999) results of $0.18( \pm 0.09)$, derived from comparison of the FTIR spectra with a reference spectrum published in a previous study that reacted $\mathrm{NO}_{3}$ directly with $\alpha$-pinene (Wängberg et al., 1997). However, due to the observation of several unidentified peaks in GC-TSD chromatograms, it is likely that we have not quantified all the organic nitrate products. If we hypothesize that all these peaks in the chromatogram that represent primary products are organic nitrates and plot each one, with an assumed sensitivity (as the average of the $\alpha$-pinene nitrate sensitivities), we determine the upper limit to the total organic nitrate yield as 0.29 . Thus, our best estimate of the overall yield of $\alpha$-pinene nitrates from $\mathrm{OH}$ reaction with $\alpha$-pinene in the presence of NO is $0.19(+0.10 /-0.06)$.

\section{$3.5 \alpha$-pinene nitrate lifetimes}

The data obtained from the $\mathrm{OH}$ radical reactions with the $\alpha$-pinene hydroxy nitrates are plotted in accordance with Eq. (1). Relative rate plots for APN-A and APN-C are shown in Fig. 6, with toluene and benzene used as a reference compound, respectively. Very good linear correlations were obtained, with $r^{2} \geq 0.97$ in both cases. The slopes of the plots were obtained by least-squares fit of the entire set of data and placed on an absolute basis using the following rate coefficients for the reference compounds: $k_{\mathrm{OH}}=$ $5.63( \pm 0.26) \times 10^{-12} \mathrm{~cm}^{3}$ molecules ${ }^{-1} \mathrm{~s}^{-1}$ for toluene and $k_{\mathrm{OH}}=1.22( \pm 0.09) \times 10^{-12} \mathrm{~cm}^{3}$ molecules ${ }^{-1} \mathrm{~s}^{-1}$ for benzene (Atkinson and Arey, 2003a). The determined $k_{\mathrm{OH}}$ values for APN-A and APN-C were $6.6( \pm 2.1) \times 10^{-12}$ and $1.2( \pm 0.4) \times 10^{-12} \mathrm{~cm}^{3}$ molecule ${ }^{-1} \mathrm{~s}^{-1}$, respectively.

These values can be compared with the calculated values from the EPA website (http://www.epa.gov/opptintr/exposure/pubs/episuite.htm) of $6.5 \times 10^{-12} \mathrm{~cm}^{3}$ molecules ${ }^{-1} \mathrm{~s}^{-1}$ and $1.0 \times 10^{-12} \mathrm{~cm}^{3}$ molecules $^{-1} \mathrm{~s}^{-1}$. To our knowledge, this is the first study of the $\mathrm{OH}$ radical reaction with 
$\alpha$-pinene hydroxy nitrates, and thus a comparison with literature values is not possible.

The main atmospheric sinks of the hydroxyalkyl nitrates are assumed to be gas-phase reactions with $\mathrm{OH}$ radicals, photolysis, and wet and dry deposition. For these compounds, photolysis is relatively unimportant, and their removal is dominated by $\mathrm{OH}$ reaction and wet deposition, depending on atmospheric conditions (Shepson et al., 1996).

On the basis of the rate coefficients determined in this study, the atmospheric lifetimes of the investigated hydroxyalkyl nitrates, with respect to their removal by reaction with $\mathrm{OH}$ radicals, are derived assuming an ambient $24 \mathrm{~h}$ average $\mathrm{OH}$ concentration of $1 \times 10^{6}$ molecules $\mathrm{cm}^{-3}$ (Prinn et al., 2005). The calculated average lifetime by reaction with $\mathrm{OH}$ radicals is 1.9 days for APN-A and 9.6 days for APN-C. It should be pointed out that the actual tropospheric lifetimes against reaction with $\mathrm{OH}$ radicals may be longer than those calculated here since the $\mathrm{OH}$ radical rate coefficients at the typical tropospheric temperature $(277 \mathrm{~K})$ are expected to be smaller than those measured during this study (296 K).

Shepson et al. (1996) indicate that the Henry's law constants for hydroxy nitrates are large enough that a significant fraction (i.e., $10-50 \%$ ) of hydroxy nitrates would be in the aqueous phase in cloud, and thus it is likely that rainout will be an important removal process for these species. Here we assume that the hydroxy nitrates are removed by wet deposition as a first-order loss process. The first order removal constant by wet deposition, $k_{\mathrm{wd}}$, is given by the following:

$k_{\mathrm{wd}}=\left(\mathrm{R}_{r} E e^{\left(-z / Z_{\mathrm{x}}\right)}\right) / Z_{\mathrm{x}}\left[(H R T)^{-1}+L_{\mathrm{wc}}\right]$

where $\mathrm{R}_{r}$ is the assumed annual rainfall rate, taken to be $3.2 \times 10^{-8} \mathrm{~m} \mathrm{~s}^{-1}\left(1 \mathrm{~m} \mathrm{yr}^{-1}\right), E$ is an enhancement factor due to droplet evaporation (assumed to be 1.33), $z$ is a characteristic height for clouds (assumed to be $3.5 \mathrm{~km}$ ), $Z_{\mathrm{x}}$ is the scale height for the species (assumed to be $1.0 \mathrm{~km}$ ), $L_{\mathrm{wc}}$ is the dimensionless liquid water content of the cloud $\left(4.2 \times 10^{-7}\right)$, and $H$ is the Henry's law constant. Assuming that the Henry's Law constant for the $\alpha$-pinene hydroxyl nitrates is similar to the average value, $5.6 \times 10^{4} \mathrm{M} \mathrm{atm}^{-1}$ at $283 \mathrm{~K}$ (a typical summer time cloudwater temperature), for $\beta$-hydroxy alkyl nitrates from Shepson et al. (1996) and Treves (2003), then the calculated $k_{\mathrm{wd}}$ is $1.1 \times 10^{-6} \mathrm{~s}^{-1}$ and the calculated (average) lifetime $\left(1 / k_{\mathrm{wd}}\right)$ for these species is 10.5 days for removal by wet deposition.

The hydroxy nitrates can also be removed from the atmosphere by dry deposition. Although there is no information in the literature on dry deposition velocities for these compounds, we might expect that dry deposition rates are significant for these difunctional nitrates. Using $v_{d}=1.0 \mathrm{~cm} \mathrm{~s}^{-1}$, and a scale height for these compounds of $1.0 \mathrm{~km}$ (as for wet removal discussed above), the first-order removal rate constant would be $k_{\mathrm{DD}}=v_{d} / Z_{X}=1.0 \times 10^{-5} \mathrm{~s}^{-1}$. Since dry deposition is unimportant at night (Shepson et al., 1996), the diurnal average first-order removal rate for dry deposition
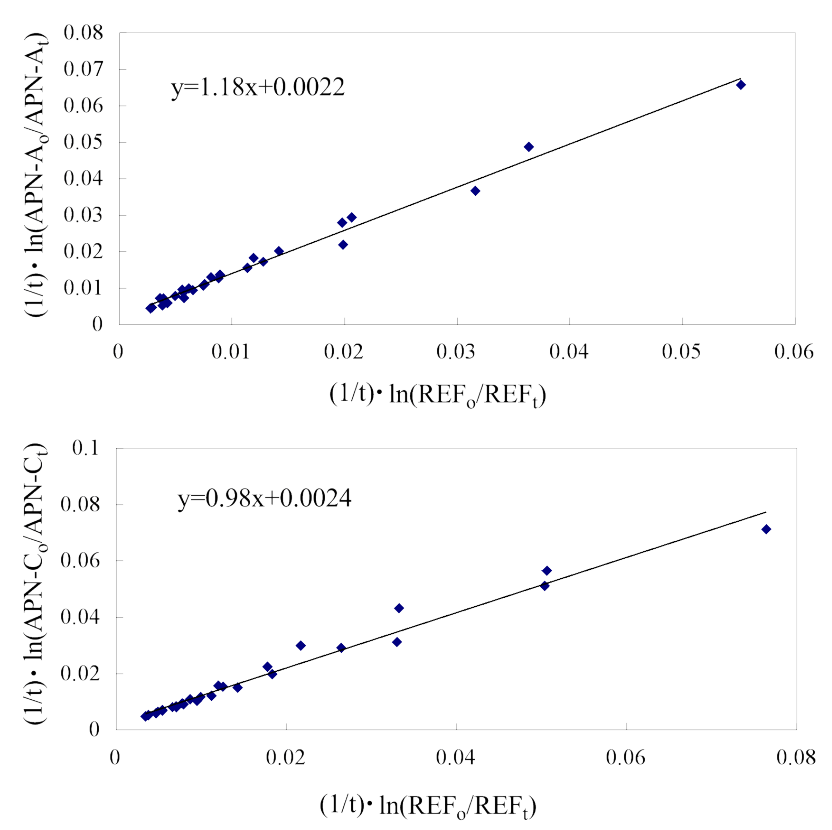

Fig. 6. $\mathrm{OH}$ rate constant data for the two $\alpha$-pinene hydroxy nitrate isomers, APN-A (top), APN-C (bottom).

can be estimated to be $1.0 \times 10^{-5} / 2=5 \times 10^{-6} \mathrm{~s}^{-1}$. We can now estimate the overall lifetime of these species in the atmosphere using Eq. (5).

$\tau_{\mathrm{APN}}=1 /\left(k_{\mathrm{OH}}[\mathrm{OH}]+k_{\mathrm{DD}}+k_{\mathrm{wd}}\right)$

For APN-A, we have $\tau_{\mathrm{APN}-A}=[(6.6+5+$ 1.1) $\times 10^{-6} \mathrm{~s}^{-1} \mathrm{~J}^{-1}=22 \mathrm{~h}$, and $38 \mathrm{~h}$ for APN-C.

Interestingly, APN-D still possesses a carbon-carbon double bond, which could, for example, react with $\mathrm{OH}$ radicals to produce significant yields of a dihydroxy dinitrooxy product (which would likely readily partition to the aerosol phase). Thus, unlike for the other three $\alpha$-pinene hydroxy nitrates identified here, it is likely that for APN-D, the reaction with $\mathrm{OH}$ and $\mathrm{O}_{3}$ will represent the most important loss route. Rate constants were calculated from the EPA website as $k_{\mathrm{OH}}=9.9 \times 10^{-11} \mathrm{~cm}^{3}$ molecules $^{-1} \mathrm{~s}^{-1}$ and $k_{\mathrm{O} 3}=4.3 \times 10^{-16} \mathrm{~cm}^{3}$ molecules ${ }^{-1} \mathrm{~s}^{-1}$. Thus the atmospheric lifetime, calculated as $1 /\left(k_{\mathrm{OH}}[\mathrm{OH}]+k_{\mathrm{O}_{3}}\left[\mathrm{O}_{3}\right]\right)$, for APN-D, where we assume $\left[\mathrm{O}_{3}\right]=1 \times 10^{12}$ molecules $\mathrm{cm}^{-3}$, is $0.5 \mathrm{~h}$. Thus we expect that, under most atmospheric conditions, APN-D will be unimportant as an organic nitrate, compared to its oxidation products (which are likely to retain the nitrooxy group).

\section{Conclusions}

The production of $\alpha$-pinene hydroxy nitrates in the presence of $\mathrm{OH}$ can sequester $\mathrm{NO}_{\mathrm{x}}$ and transport it to the regional troposphere. The relatively long residence time of individual 
APNs $(0.5-38 \mathrm{~h})$ in the atmosphere makes it appropriate to include in regional and global atmospheric chemistry models. The reaction of $\mathrm{OH}$ radicals with $\alpha$-pinene can produce at least seven organic nitrates, which will likely partition to the aerosol phase, as observed by Rollins et al. (2010b). Four $\alpha$-pinene hydroxy nitrates were identified in the smog chamber experiments and reported here: 2-hydroxypinene3-nitrate (APN-A), 3-hydroxypinene-2-nitrate (APN-B), 6hydroxy -1,7,7-trimethyl bicyclo[2.2.1]heptan-2-yl nitrate (APN-C), and 6-hydroxymenthen-8-nitrate (APN-D). These studies suggest that a variety of organic nitrates and/or secondary organic nitrates could be formed in the gas phase and serve as a reservoir for $\mathrm{NO}_{\mathrm{x}}$. The individual $\alpha$ pinene hydroxy nitrate yields from reaction of $\mathrm{OH}$ radical with $\alpha$-pinene in the presence of $\mathrm{NO}$ were as follows: $0.027( \pm 0.011)$ for APN-A, 0.022 $( \pm 0.008)$ for APN$\mathrm{B}, 0.049( \pm 0.019)$ for APN-C, and $0.031( \pm 0.013)$ for APND. However, the total organic nitrate yield is estimated to be $0.19(+0.10 /-0.06)$. The atmospheric lifetimes of these nitrates are on the order of hours to days, making it possible for them to contribute to $\mathrm{NO}_{\mathrm{y}}$ and atmospheric transport of nitrogen. Furthermore, they may contribute significantly to aerosol mass, and especially for APN-D, could react further in the aerosol phase, e.g. with sulfate radicals, $\mathrm{SO}_{4}^{-}$, as discussed by Nozière et al. (2010). In the future, we intend to measure the concentration of $\alpha$-pinene hydroxy nitrates in the aerosol phase and their gas/particle partitioning coefficients as well as the free $\mathrm{NO}_{2}$ yield from $\mathrm{OH}$ reaction with the $\alpha$-pinene nitrates.

Acknowledgements. We gratefully acknowledge support by the National Science Foundation grant, No. ATM0542701, and EPA (STAR Grant R833750).

Edited by: R. Cohen

\section{References}

Andreae, M. O. and Crutzen, P. J.: Atmospheric aerosols: Biogeochemical sources and role in atmospheric chemistry, Science, 276, 1052-1058, 1997.

Arey, J., Aschmann,S. M., Kwok, E. S. C., and Atkinson, R.: Alkyl nitrate, hydroxyalkyl nitrate, and hydroxycarbonyl formation from the NOx-air photooxidations of $\mathrm{C}_{5}-\mathrm{C}_{8} n$-alkanes, J. Phys. Chem. A, 105, 1020-1027, 2001.

Aschmann, S. M., Reissell, A., Atkinson, R., and Arey, J.: Products of the gas phase reactions of the $\mathrm{OH}$ radical with $\alpha$ - and $\beta$-pinene in the presence of NO, J. Geophys. Res., 103, 25,553-25,561, 1998.

Aschmann, S. M., Arey, J., and Atkinson, R.: Atmospheric chemistry of three C10 alkanes, J. Phys. Chem., 105, 7598-7606, 2001.

Aschmann, S. M., Atkinson, R., and Arey, J.: Products of reaction of $\mathrm{OH}$ radicals with $\alpha$-pinene, J. Geophys. Res., 107(D14), 4191-4197, 2002.
Aschmann, S. M. and Atkinson, R.: Rate constants for the gasphase reactions of $\mathrm{OH}$ radicals with $E$-7-tetradecene, 2-methyl1-tridecene and the $\mathrm{C}_{7}-\mathrm{C}_{14} 1$-alkenes at $295 \pm 1 \mathrm{~K}$, Phys. Chem. Chem. Phys., 10, 4159-4164, 2008.

Atkinson, R. and Arey, J.: Atmospheric degradation of volatile organic compounds, Chem. Rev., 103, 4605-4638, 2003 a.

Atkinson, R. and Arey, J.: Gas-phase tropospheric chemistry of biogenic volatile organic compounds: a review, Atmos. Environ., 37, S197-S219, 2003b.

Atkinson, R., Aschmann, S. M., Carter, W. P. L., Winer, A. M., and Pitts Jr., J. N.: Alkyl nitrate formation form the $\mathrm{NO}_{\mathrm{x}}$-air photooxidations of $\mathrm{C}_{2}-\mathrm{C}_{8}$ n-alkanes, J. Phys. Chem., 86, 45634569, 1982.

Barker, J. R., Lohr, L. L., Shroll, R., and Reading, S.: Modeling the organic nitrate yields in the reaction of alkyl peroxy radicals with nitric oxide. 2. reaction simulations, J. Phys. Chem. A, 107, 7434-7444, 2003.

Constantino, M. G., Lacerda, V., Invernize, P. R., da Silva, L. C., and da Silva, G. V. J.: Opening of Epoxide Rings Catalyzed by Niobium Pentachloride, Synthetic Commun., 37, 3529-3539, 2007.

Espada, C., Grossenbacher, J., Ford, K., Couch, T., and Shepson, P. B.: The Production of Organic Nitrates from Various Anthropogenic Volatile Organic Compounds, Int. J. Chem. Kinet, 37, 675-685, 2005.

Grosjean, D., Williams II, E. L., and Seinfeld, J. H.: Atmospheric oxidation of selected terpenes and related carbonyls: Gas-phase carbonyl products, Environ. Sci. Technol., 26, 1526-1533, 1992.

Guenther, A. B., Zimmerman, P. R., Harley, P. C., Monson, R. K., and Fall, R.: Isoprene and monoterpene emission ratevariabilitymodel evaluations and sensitivity analyses, J. Geophys. Res., 98, 12609-12617, 1993.

Guenther, A., Karl, T., Harley, P., Wiedinmyer, C., Palmer, P. I., and Geron, C.: Estimates of global terrestrial isoprene emissions using MEGAN (Model of Emissions of Gases and Aerosols from Nature), Atmos. Chem. Phys., 6, 3181-3210, doi:10.5194/acp-63181-2006, 2006.

Hakola, H., Arey, J., Aschmann, S. M., and Atkinson, R.: Product formation from the gas-phase reactions of $\mathrm{OH}$ radicals and $\mathrm{O}_{3}$ with a series of monoterpenes, J. Atmos. Chem., 18(1), 75-102, 1994.

Hatakeyama, S., Izumi, K., Fukuyama, T., Akimoto, H., and Washida, N.: reaction of $\mathrm{OH}$ with $\alpha$-pinene and $\beta$-pinene in air: estimate of global $\mathrm{CO}$ production from the atmospheric oxidation of terpenes, J. Geophys. Res., 96, 947-958, 1991.

Horowitz, L. W., Fiore, A. M., Milly, G. P., Cohen, R. C., Perring, A., Wooldridge, P. J., Hess, P. G., Emmons, L. K., and Lamarque, J. F.: Observational constraints on the chemistry of isoprene nitrates over the eastern United States, J. Geophys. Res., 12, D12S08, doi:10.1029/2006JD007747, 2007.

Isaksen, I. S. A. and Hov., O.: Calculation of trends in the tropospheric concentration of ozone, hydroxyl, carbon monoxide, methane, and nitrogen oxides, Tellus, 39B, 271-285, 1987.

Kalabokas, P., Bartzis, J. G., Bomboi, T., Ciccioli, P., Cieslik, S., Dlugi, R., Foster, P., Kotzias, D., and Steinbrecher, R.: Ambient atmospheric trace gas concentrations and meteorological parameters during the first BEMA measuring campaign on May 1994 at Castelporziano, Italy, Atmos. Environ., 31, S1, 67-77, 1997.

Kwok, E. S. C. and Atkinson, R.: Estimation of hydroxyl radical 
reaction rate constants for gas-phase organic compounds using a structure-reactivity relationship: an update, Atmos. Environ., 29(14), 1685-1695, 1995.

Larsen, B. R., Di Bella, D., Glasius, M., Winterhalter, R., Jensen, N. R., and Hjorth, J.: Gas-phase $\mathrm{OH}$ oxidation of monoterpenes: gaseous and particulate products, J. Atmos. Chem., 38, 231-276, 2001.

Lee, A., Goldstein, A. H., Kroll, J. H., Ng, N. L., Varutbangkul, V., Flagan, R. C., and Seinfeld, J. H.: Gas-phase products and secondary aerosol yields from the photooxidation of 16 different terpenes, J. Geophys. Res., 111, D17305, 1-25, 2006.

Librando, V. and Tringali, G.: Atmospheric fate of $\mathrm{OH}$ initiated oxidation of terpenes. reaction mechanism of $\alpha$-pinene degradation and secondary organic aerosol formation, J. Environ. Manage., 75, 275-282, 2005.

Matsunaga, A. and Ziemann, P. J.: Yields of $\beta$-hydroxynitrates, dihydroxynitrates, and trihydroxynitrates formed from $\mathrm{OH}$ radicalinitiated reactions of 2-methyl-1-alkenes, Proc. Natl. Acad. Sci., 107, 6664-6669, 2010.

Monks, P. S., Granier, C., Fuzzi, S., Stohl, A., Williams, M. L., Akimoto, H., Amann, M., Baklanov, A., Baltensperger, U., Bey, I., Blanke, N., Blake, R. S., Carslaw, K., Cooper, O.R., Dentener, F., Fowler, D., Fragkou, E., Frost, G.J., Generoso, S., Ginoux, P., Grewe, V., Guenther, A., Hansson, H. C., Henne, S., Hjorth, J., Hofzumahaus, A., Huntrieser, H., Isaksen, I. S. A., Jenkin, M. E., Kaiser, J., Kanakidou, M., Klimont, Z., Kulmala, M., Laj, P., Lawrence, M. G., Lee, J. D., Liousse, C., Maione, M., McFiggans, G., Metzger, A., Mieville, A., Moussiopoulos, N., Orlando, J. J., O' Dowd, C.D., Palmer, P. I., Parrish, D. D., Petzold, A., Platt, U., Pöschl, U., Prévôt, A. S. H., Reeves, C. E., Reimann, S., Rudich, Y., Sellegri, K., Steinbrecher, R., Simpson, D., ten Brink, H., Theloke, J., van der Werf, G.R., Vautard, R., Vestreng, V., Vlachokostas, Ch., and von Glasow, R.: Atmospheric composition change: global and regional air quality, Atmos. Environ., 43, 5268-5350, 2009.

Muthuramu, K., Shepson, P., and O'Brien J.: Preparation, analysis, and atmospheric production of multifunctional organic nitrates, Environ. Sci. Technol., 27, 1117-1124, 1993.

Nozière, B., Barnes, I., and Becker, K. H.: Product study and mechanisms of the reactions of $\alpha$-pinene and pinonaldehyde with $\mathrm{OH}$ radicals, J. Geophys. Res., 104, 23,645-23,656, 1999.

Nozière, B., Ekström, S., Alsberg, T., and Holmström, S.: Radical-initiated formation of organosulfates and surfactants in atmospheric aerosols, Geophys. Res. Lett., 37, L05806, doi:10.1029/2009GL041683, 2010.

O’Brien, J. M., Czuba, E., Hastie, D. R., Francisco, J. S., and Shepson, P. B.: Determination of the hydroxy nitrate yields from the reaction of $\mathrm{C} 2-\mathrm{C} 6$ alkenes with $\mathrm{OH}$ in the presence of NO, J. Phys. Chem. A, 102, 8903-8908, 1998.

Orlando, J. J., Nozière, B., Tyndall, G. S., Orzechowska, G. E., Paulson, S. E., and Rudich, Y.: Product studies of OH- and ozone-initiated oxidation of some monoterpenes, J. Geophys. Res., 105, 11561-11572, 2000.

Owen, S., Boissard, C., Street, R. A., Duckham, S. C., Csiky, O. and Hewitt, N. C.: Screening of 18 Mediterranean plant species for volatile organic compound emissions, Atmos. Environ., 31, S1, 101-117, 1997.

Pathak, R. K., Presto, A. A., Lane, T. E., Stanier, C. O., Donahue, N. M., and Pandis, S. N.: Ozonolysis of a-pinene: parameterization of secondary organic aerosol mass fraction, Atmos. Chem. Phys., 7, 3811-3821, doi:10.5194/acp-7-3811-2007, 2007.

Peeters, J., Vereecken, L., and Fantechi, G.: The detailed mechanism of the $\mathrm{OH}$ initiated atmospheric oxidation of $\alpha$-pinene: a theoretical study, Phys. Chem. Chem. Phys., 3, 5489-5504, 2001.

Prinn, R. G., Huang, J., Weiss, R. F., Cunnold, D. M., Fraser, P. J., Simmonds, P. G., McCulloch, A., Harth, C., Reimann, S., Salameh, P., O’Doherty, S., Wang, R. H. J., Porter, L. W., Miller, B. R., and Krummel, P. B.: Evidence for variability of atmospheric hydroxyl radicals over the past quarter century, Geophys. Res. Lett., 32, L07809, doi:10.1029/2004GL022228, 2005.

Reissell, A., Harry, Ch., Aschmann, S.H., Atkinson, R., and Arey, J.: Formation of acetone from the $\mathrm{OH}$ radical- and $\mathrm{O}_{3}$-initiated reactions of a series of monoterpenes, J. Geophys. Res., 104(13), 13869-13,880, 1999.

Rollins, A. W., Fry, J. L., Hunter, J. F., Kroll, J. H., Worsnop, D. R., Singaram, S. W., and Cohen, R. C.: Elemental analysis of aerosol organic nitrates with electron ionization highresolution mass spectrometry, Atmos. Meas. Tech., 3, 301-310, doi:10.5194/amt-3-301-2010, 2010a.

Rollins, A. W., Smith, J. D., Wilson, K. R., and Cohen, R. C.: Real time in situ detection of organic nitrates in atmospheric aerosols, Enivron. Sci. Technol., 44, 5540-5545, 2010b.

Ruppert, L., Becker, K.H., Nozière, B., and Spittler, M.: Development of monoterpene oxidation mechanisms: results from laboratory and smog chamber studies, in: Transport and Chemical Transformation in the Troposphere, edited by: Borrell, P. M., Borrell, P., Proceedings of the EUROTRAC-2 Symposium, 8, 63-68, 1999.

Shepson, P. B., Mackay, E., and Muthuramu, K.: Henry's law constants and removal processes for several atmospheric $\beta$-hydroxy alkyl nitrates, Environ. Sci. Technol., 30, 3618-3623, 1996.

Steinbrecher, R., Smiatek, G., Köble, R., Seufert, G., Theloke, J., Hauff, K., Ciccioli, P., Vautard, R., and Curci, G.: Intra- and inter-annual variability of VOC emissions from natural and seminatural vegetation in Europe and neighboring countries, Atmos. Environ., 43(7), 1380-1391, 2009.

Seufert, G., Bartzis, J., Bomboi, T., Ciccioli, P., Cieslik, S., Dlugi, R., Foster, P., Hewitt, C. N., Kesselmeier, J., Kotzias, D., Lenz, R., Manes, F., Perez Pastor, R., Steinbrecher, R. Torres, L., Valentin, R. and Versino, B.: An overview of the Castelporziano experiments, Atmos. Environ., 31, S1, 5-17, 1997.

Treves, K. and Rudich, Y.: The atmospheric fate of C3-C6 hydroxyalkyl nitrates, J. Phys. Chem. A, 107, 7809-7817, 2003.

Vereecken, L., Muller, J. F., and Peeters, J.: Low-volatility polyoxygenates in the $\mathrm{OH}$-initiated atmospheric oxidation of $\alpha$ pinene: impact of non-traditional peroxyl radical chemistry, Phys. Chem. Chem. Phys., 9, 5241-5248, 2007.

Vinckier, C., Compernolle, F., Saleh, A. M., Van Hoof, N., and Van Hees, I.: Product yields of the $\alpha$-pinene reaction with hydroxyl radicals and the implication on the global emission of trace compounds in the atmosphere, Fresen. Environ. Bull., 7, 361-368, 1998.

Vanhees, I., Van den Bergh, V., Schildermans, V. R., De Boer, R., Compernolle, F., and Vinckier, C.: Determination of the oxidation products of the reaction between a-pinene and hydroxyl radicals by high-performance liquid chromatography, J. Chromatogr. A, 915, 75-83, 2001. 
Van den Bergh, V., Vanhees, I., De Boer, R., Compernolle, F., and Vinckier, C.: Identification of the oxidation products of the reaction between a-pinene and hydroxyl radicals by gas and highperformance liquid chromatography with mass spectrometric detection, J. Chromatogr. A, 896, 135- 148, 2000.

Wängberg, I., Barnes, I., and Becker, K. H.: Product and mechanistic study of the reaction of $\mathrm{NO}_{3}$ radicals with $\alpha$ - pinene, Environ. Sci. Technol., 31, 2130-2135, 1997.
Wisthaler, A. Jensenb, N. R., Winterhalterb, R., Lindingera, W., and Hjorthb, J.: Measurements of acetone and other gas phase product yields from the $\mathrm{OH}$-initiated oxidation of terpenes by proton-transfer-reaction mass spectrometry (PTR-MS), Atmos. Environ., 35, 6181-6191, 2001.

Zhang, J., Dransfield, Y., and Donahue, N. M.: On the Mechanism for Nitrate Formation via the Peroxy Radical + NO reaction, J. Phys. Chem. A, 108, 9082-9095, 2004. 